\title{
Non-tuberculous mycobacterium affecting adults in Eastern India: Case series from a resource limited tertiary care setting
}

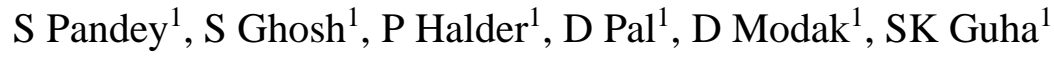 \\ Sri Lankan Journal of Infectious Diseases 2019 Vol.9 (2):146-151 \\ DOI: http://doi.org/ 10.4038/sljid.v9i2.8263
}

\begin{abstract}
Non-tuberculous mycobacteria (NTM) are among the less commonly reported causes of infection which are being increasingly reported owing to better diagnostic tools and physician awareness. We report a series of six patients presenting to the Department of Tropical Medicine, School of Tropical Medicine, West Bengal, India over a one year period (20172018) who were diagnosed with NTM infection by culture of pus samples or bone marrow aspirates. Identification of NTM was carried out by initial Ziehl Neelsen staining followed by culture and DNA sequencing of isolates for species identification. Of the six patients, two were HIV positive.
\end{abstract}

Mycobacterium avian complex (MAC) and M. Senegalese were isolated from one patient each and M. abscessus from the remaining 4 patients. All patients were treated using the standard guidelines for periods of 6 to 12 months. Clinical response was noted after 1 to 2 months of therapy with complete response around 3 to 6 months. No relapse was noted during a 9 month follow up.

DNA sequencing provided a significant advantage for diagnosis and enabled appropriate treatment with a good outcome on these six patients.

Non-responding surgical site infections and disseminated infection in HIV patients not responding to anti-tuberculous and antifungal therapy should be considered for diagnosis of NTM.

Keywords: Nontuberculous mycobacterium (NTM), M. abscessus, M. Senegalese, HIV, Surgical site infection

\footnotetext{
${ }^{1}$ Department of Tropical Medicine, School of Tropical Medicine, C R Avenue Road, Kolkatta-700073, West Bengal, India

Address for correspondence: Dr Saurabh Pandey, Department of Tropical Medicine, School of Tropical Medicine, C R Avenue Road, Kolkatta-700073, West Bengal, India. Telephone: +9073321386

Email: saurbhp2013@gmail.com (iD https://orcid.org/0000-0001-5600-6346

Received 20 August 2019 and revised version accepted 3 October 2019 


\section{Introduction}

NTM is an emerging infectious disease in India and across the world ${ }^{1-10}$ which is attributed to better diagnostic tools, especially DNA sequencing. ${ }^{7}$ NTM infection mimics tuberculosis, therefore necessitating culture and molecular methods for species identification. Pulmonary or surgical site infections are the usual sites of NTM infections among immune-competent patients but are more likely to be systemic in the immune-compromised hosts such as those who are infected with the Human Immunodeficiency Virus (HIV). ${ }^{11}$ Surgical procedures, preexisting lung disease and immunosuppression predispose to infections by NTM as they are ubiquitously distributed in nature and thereby the main source of human infection. ${ }^{8}$ NTM infections have a protracted course and require prolonged treatment and appropriate surgical debridement.

\section{Case reports}

Six patients were diagnosed as having NTM infection in 2017 in our centre which is a major referral centre for tropical infectious diseases in Eastern India.

A detailed history including drug treatment, clinical examination and general investigation was documented in all patients referred to our centre. All the clinical specimens received were subjected to smear microscopy using Ziehl-Neelsen (ZN) staining, fungal stain and Gram stain. All samples were then inoculated into BacT/ALERT 3D system containing modified Middlebrook $7 \mathrm{H} 9$ media along with fungal culture and bacterial culture media. All cultures which had growth in the mycobacterial culture were subjected to $\mathrm{ZN}$ staining and molecular testing by DNA sequencing of $16 \mathrm{~S}$ rRNA gene regions.

Patients who were identified with an NTM infection were offered treatment according to ATS-IDSA guidelines ${ }^{12,13}$ for NTM infection. These patients were followed up for a minimum period of 9 months. Response to treatment and relapse were recorded. No follow up culture was done due to financial constraints.

\section{Case 1}

A 38 year old female had persistent discharge (Fig.1) for a period of one and half months from the surgical site of her open cholecystectomy (CCT). She already had 1 month monotherapy with clarithromycin and then she was diagnosed with NTM. There was no visible discharge at the 3 month follow up visit and treatment was continued for 12 months.

\section{Case 2}

A 42 year old female developed a small abscess 3 days following an intramuscular injection 1 month

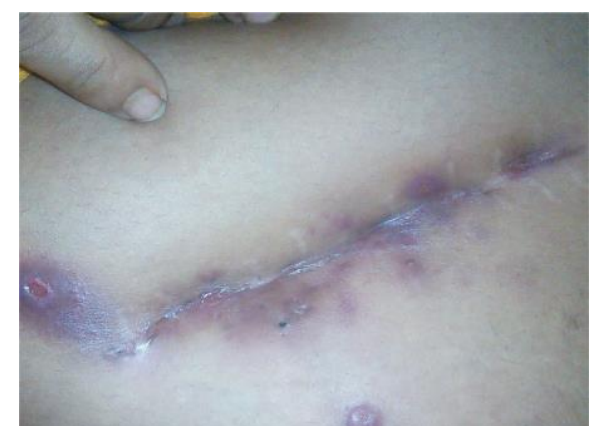

Fig 1: Open cholecystectomy scar showing pus pockets along incision line on day 1 previously and had received 12 days of clarithromycin at her visit to us. She responded to treatment which was continued for 6 months (Fig. 2).

\section{Case 3}

A 44 year old man had persistent pus with sinus formation at the incision site (Fig. 3) following a laparotomy 2 months previously. He had already received 45 days of 
clarithromycin and a few days of levofloxacin at his visit. He responded to treatment which was continued for 6 months.

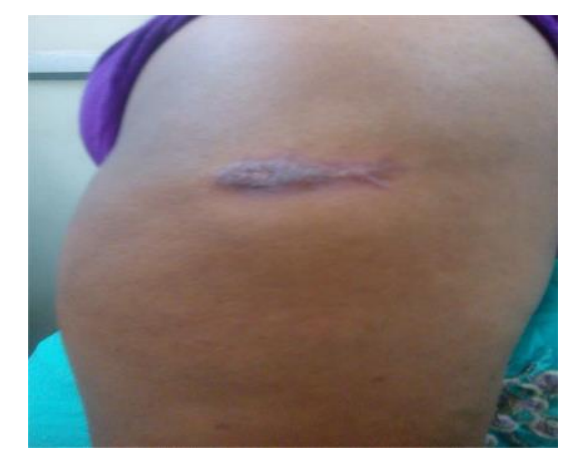

Fig. 2: Mild pus at the intramuscular injection site with sinus

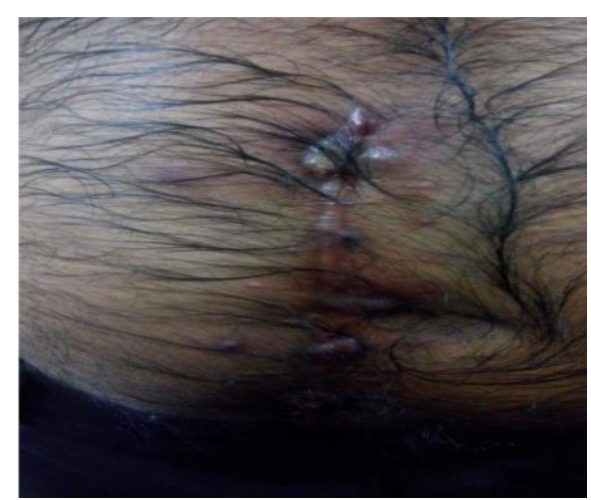

Fig. 3: Laparotomy scar showing pus pocket on $1^{\text {st }}$ visit

\section{Case 4}

A 53 year old lady presented with multiple pus discharging sinuses for one year post laparoscopic cholecystectomy (Fig. 4). She had received 6 months of suboptimal dose therapy of clarithromycin and a few days of levofloxacin and amikacin before visiting us. She responded to treatment which was continued for 12 months.

\section{Case 5}

A 48 year old HIV positive man presented with pyrexia of 2 months duration associated with an evening rise of temperature, weight loss and associated lower respiratory tract infection. He had multiple retro-peritoneal lymph nodes and was started on anti-tubercular treatment without

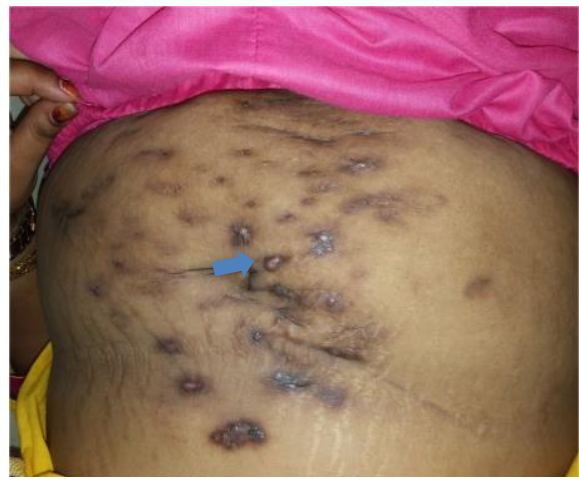

Fig. 4: $1^{\text {st }}$ day visit - 2 spots of fluid discharge from laparoscopy port site any response even after 4 weeks. A bone marrow sample was cultured for mycobacteria and fungi from which M. avium complex (MAC) was isolated. He became afebrile 2 weeks after initiation of treatment with significant relief after 2 months. No relapse had occurred on follow up at 12 months.

\section{Case 6}

A 16 year old boy newly diagnosed with HIV disease presented with fever for 2 months. There were associated night sweats and evening rise of temperature. He was anaemic (haemoglobin:8.2/g/dl) and had multiple retroperitoneal lymph nodes and mild splenomegaly. He had received 2 months of empiric anti-tuberculous drugs (ATD) without any significant improvement. He refused bone marrow testing or lymph node FNAC initially. He was treated with amphotericin B deoxycholate $1 \mathrm{mg} / \mathrm{kg} / \mathrm{day}$ for 2 weeks without any improvement. Culture of bone marrow was taken after 3 weeks of admission which grew M abscessus. He was treated and began to show response after 2 weeks and significantly improved after 1 month of therapy. No relapse occurred within 9 months. 
Clinical characteristics along with treatment offered is shown in Table I.

Table 1: Characteristics and profile of patients infected with NTM

\begin{tabular}{|c|c|c|c|c|c|c|}
\hline INDICES & CASE 1 & CASE 2 & CASE 3 & CASE 4 & CASE 5 & CASE 6 \\
\hline Predisposition & $\begin{array}{l}\text { Laparoscopic } \\
\text { surgery }\end{array}$ & $\begin{array}{c}\text { Intramuscular } \\
\text { injection }\end{array}$ & $\begin{array}{l}\text { Laparotomy } \\
\text { incision }\end{array}$ & $\begin{array}{l}\text { Laparoscopic } \\
\text { surgery }\end{array}$ & HIV & HIV \\
\hline $\begin{array}{l}\text { Complaint } \\
\text { duration } \\
\text { (months) }\end{array}$ & 1.5 & 1 & 2.5 & 12 & 3 & 2 \\
\hline Presentation & $\begin{array}{c}\text { Persistent } \\
\text { discharge at } \\
\text { surgical site }\end{array}$ & $\begin{array}{l}\text { Pus formation } \\
\text { at injection } \\
\text { site }\end{array}$ & $\begin{array}{l}\text { Pus formation at } \\
\text { surgical site }\end{array}$ & $\begin{array}{c}\text { Persistent } \\
\text { discharge - } \\
\text { surgical site }\end{array}$ & $\begin{array}{c}\text { Pyrexia of } \\
\text { unknown origin }\end{array}$ & $\begin{array}{c}\text { Pyrexia of } \\
\text { unknown origin }\end{array}$ \\
\hline $\begin{array}{l}\text { Clarithromycin } \\
\text { duration (days) }\end{array}$ & 30 & 12 & 45 & 180 & No & No \\
\hline $\begin{array}{l}\text { Initial } \\
\text { antibiotics } \\
\text { received }\end{array}$ & $\begin{array}{l}\text { Amoxicillin, } \\
\text { Ciprofloxacin }\end{array}$ & None & $\begin{array}{c}\text { Amikacin, } \\
\text { Levofloxacin }\end{array}$ & $\begin{array}{l}\text { Amikacin, } \\
\text { Amoxicillin }\end{array}$ & $\begin{array}{l}\text { Piperacillin/ } \\
\text { Tazobactum, }\end{array}$ & $\begin{array}{l}\text { Piperacillin, } \\
\text { Vancomycin }\end{array}$ \\
\hline ATD history & No & No & No & Yes & Yes & Yes \\
\hline Sample & Pus & Pus & Pus & Pus & $\mathrm{BM}$ aspirate & $\begin{array}{l}\text { FNAC lymph } \\
\text { node }\end{array}$ \\
\hline Species & M. abscessus & $\begin{array}{c}M . \\
\text { senegalenese }\end{array}$ & M. abscessus & M. abscessus & $M A C$ & M. abscessus \\
\hline Treatment given & $\begin{array}{c}\text { CL 500mg BD, } \\
\text { C-DS OD } \\
\text { L 750mg OD }\end{array}$ & $\begin{array}{c}\text { CL 500mg } \\
\text { BD } \\
\text { E } 800 \mathrm{mg} \text { OD } \\
\text { L } 750 \mathrm{mg} \text { OD }\end{array}$ & $\begin{array}{c}\text { CL 500mg BD } \\
\text { C-DS OD } \\
\text { L 750mg OD }\end{array}$ & $\begin{array}{c}\text { CL 500mg BD } \\
\text { A 1gm OD } \\
\text { C-DS OD } \\
\text { L 750mg OD }\end{array}$ & $\begin{array}{l}\text { CL 500mg BD } \\
\text { R } 600 \mathrm{mg} \text { OD } \\
\text { E } 800 \mathrm{mg} \text { OD }\end{array}$ & $\begin{array}{c}\text { CL 500mg } \\
\text { E } 800 \mathrm{mg} \mathrm{OD} \\
\text { A } 1 \mathrm{gm} \mathrm{OD}\end{array}$ \\
\hline $\begin{array}{l}\text { Complete } \\
\text { response } \\
\text { (months) }\end{array}$ & 2 & 1 & 3 & 4 & 1.5 & 1 \\
\hline $\begin{array}{l}\text { Associated } \\
\text { comorbidity }\end{array}$ & none & HTN. T2DM & none & T2DM & HIV, COPD & HIV \\
\hline
\end{tabular}

CL- Clarithromycin; L- Levofloxacin; A- Amikacin; C-DS- Cotrimoxazole-double strength; E- Ethambutol OD- Once daily; R- Rifampcin HTN- Hypertension; COPD- Chronic obstructive Pulmonary Disease ; T2DM- Type 2 Diabetes Mellitus; BD- Twice daily

\section{Discussion}

NTM is a chronic granulomatous infection similar in presentation to tuberculosis but with less morbidity. Since they do not respond completely to standard ATD, culture and DNA sequencing are required for definite diagnosis. ${ }^{7}$ There is an increase in use of histopathology, advance culture technique and DNA sequencing for species level diagnosis which has led to increased reporting of NTM infections. ${ }^{3}$ The estimated incidence of NTM from different geographical locations in India is $3.4 \%$ to $24.7 \% .{ }^{1-10}$ The defined risk populations expected to harbour NTM are immune-compromised patients including patients with HIV infection and diabetes mellitus, pre-existing lung cavitation, old age, recent surgery or penetrating injury..$^{7-8}$ The disease spectrum of NTM is divided into chronic pulmonary infections, superficial lymphadenitis, skin and skeletal infections, and disseminated disease. ${ }^{8}$ Among HIV infected patients, clinical presentation is nonspecific and mimics tuberculosis. ${ }^{7}$

The predominant species in India as cited by Indian studies are the rapid growers $M$. abscessus and M. fortuitum. Other commonly reported species are M. intracellulare, $M$. chelonae, MAC, M. kansasii, M. gordonae, and M. scrofulaceum. ${ }^{1-5} \mathrm{~S}$ Khatter et al reported a predominance of $M A C, M$. abscessus and M. fortuitum in their study of an HIV infected population. ${ }^{11}$ In our series M. abscessus was the commonest species, agreeing with previous 
Indian data. M senegalese was an uncommon finding and did not corroborate with other studies.

NTM only responds to rifampicin and ethambutol of the standard ATDs. Second line agents, especially aminoglycosides, macrolides, quinolones, and other drugs - doxycycline, sulphonamides and carbapenems - are included in the IDSA recommendations for treatment of NTM infections. $M$ abscessus is treated with drugs along with surgical resection and MAC lymphadenopathy is treated with excision and drugs in non-responding cases. The ATS-IDSA guidelines suggest a duration of treatment for 1 year for treatment of NTM infections except for disseminated and lymph node infections caused by MAC. ${ }^{12,13}$

The cumulative outcome of NTM infections has been considered as good with appropriate therapy and surgical intervention whenever required. ${ }^{2}$ A study from Southern India on surgical site infection with NTM in 24 patients showed a favourable outcome in 22 cases after appropriate antibiotics and debridement. ${ }^{10}$ Similarly our patients with post-surgical infection had a good outcome without relapse at around 1 year. Another study by M K Gundayada et al. on surgical site infection had a good outcome with complete cure in all patients. ${ }^{8}$ One possible reason for these post-operative surgical site infections in the Indian setting could be the use of $2.5 \%$ gluteraldehyde for disinfection and use of boiled water for cleansing of instruments. ${ }^{10}$

NTM in AIDS can present as localized or disseminated disease. McCarthy et al showed a prevalence of $2 \%$ among HIV patients group with $34 \%$ as pulmonary and $5 \%$ as disseminated diseases. ${ }^{14}$ It sometimes present as the Immune Reconstitution Inflammatory Syndrome (IRIS) after initiation of antiretroviral therapy (ART). ${ }^{15}$

All our patients responded well to treatment and there were no adverse drug reaction during follow up. In this background this case series becomes important as it provides follow up response to therapy and appropriate use of DNA sequencing of isolates in all culture positive cases.

\section{Conclusion}

NTM are emerging infections especially in the Indian context. Skin or soft tissue infections not responding to antibiotics and antitubercular therapy must be cultured and DNA sequencing should be offered for specific diagnosis. Similarly, NTM should be suspected in HIV infected persons with disseminated infection not responding to antituberculous and fungal therapy. A prolonged course of macrolide based combination therapy generally has a good response and outcome is excellent.

Ethical consent: Informed consent was taken from the patient as proof of their permission to participate in the reporting.

Conflict of interest: There was no conflict of interest

\section{References}

1. Jain S, Sankar MM, Sharma $\mathrm{N}$ et al. High prevalence of non-tuberculous mycobacterial disease among non-HIV infected individuals in a TB endemic country--experience from a tertiary centre in Delhi, India. Pathog Glob Health. 2014; 108(2):118-22. 
doi: https://doi.org/10.1179/2047773214y.0000000133

2. Desikan P, Tiwari K, Panwalkar N, et al. Public health relevance of non-tuberculous mycobacteria among AFB positive sputa. GERMS. 2017; 7(1):10-18.

doi: https://doi.org/10.18683/germs.2017.1103

3. A. K. Maurya, V. L. Nag, S. Kant, et al, "Prevalence of nontuberculous mycobacteria among extrapulmonary tuberculosis cases in tertiary care centers in northern India. BioMed Research International. 2015, 2015; Article ID 465403. doi: https://doi.org/10.1155/2015/465403

4. Tapti S, Parijat D, Tirthankar S. Epidemiology and drug resistance of non-tuberculous mycobacteria in India: a mini review. Biostat Biometrics Open Acc J. 2017; 1(4):555568 doi: https://doi.org/10.19080/bboaj.2017.01.555568

5. Gopinath K, Singh S. Non-tuberculous mycobacteria in TB-endemic countries: Are we neglecting the danger? PLoS Negl Trop Dis 2010; 4(4): e615. doi: https://doi.org/10.1371/journal.pntd.0000615

6. Shah A K, Gambhir R. P. S., Hazra N et al. Non- tuberculous mycobacteria in surgical wounds- a rising cause of concern? Indian J Surg 2010; 72:206-210 doi: https://doi.org/10.1007/s12262010-0057-9

7. Umrao J, Singh D, Zia A, et al. Prevalence and species spectrum of both pulmonary and extrapulmonary nontuberculous mycobacteria isolates at a tertiary care center. Int $J$ Mycobacteriol. 2016; 5(3):288-293. doi: https://doi.org/10.1016/j.ijmyco.2016.06.008

8. Gundavda MK, Patil HG, Agashe VM, et al. Nontuberculous mycobacterial infection of the musculoskeletal system in immunocompetent hosts. Indian J Orthop 2017; 51:205-12. doi: $10.4103 / 0019-5413.201718$

9. Karak K, Bhattacharyya S, Majumdar S, et al. Pulmonary infection caused by Mycobacteria other than M. tuberculosis in and around Calcutta. Indian J Pathol Microbiol. 1996; 39(2):131-4. PubMed PMID: 9401242.

10. Krishnappa R, Samrasam I. Atypical mycobacterial infection in post laparoscopy surgical wounds: our observations and review of literature Int Surg J. 2017;4(9):2943-2946 doi: https://doi.org/10.18203/2349-2902.isj20173875

11. Khatter S, Singh UB, Arora J, et al. Mycobacterial infections in human immuno-deficiency virus seropositive patients: role of non-tuberculous mycobacteria. Indian J Tuberc. 2008; 55(1):28-33. PMID: 18361308

12. Griffith DE., Aksamit T., Brown-Elliott B.A., et al An official ATS/IDSA statement: diagnosis, treatment, and prevention of nontuberculous mycobacterial diseases, Am. J. Respir. Crit. Care Med. 2007; 175:367-416. doi: https://doi.org/10.1164/rccm.200604-571st

13. Stevens DL, Bisno AL, Chambers HF et al Infectious Diseases Society of America. Practice guidelines for the diagnosis and management of skin and soft tissue infections: 2014 update by the Infectious Diseases Society of America. Clin Infect Dis. 2015; 59(2):e10-52. doi: https://doi.org/10.1093/cid/civ113

14. McCarthy KD, Cain KP, Winthrop KL, et al. Nontuberculous mycobacterial disease in patients with HIV in Southeast Asia. Am J Respir Crit Care Med. 2012; 185(9):981-8. doi: https://doi.org/10.1164/rccm.201107-1327oc

15. Shah A, Stani A, Adalja M, et al. Immune reconstitution disease or mycobacteria other than tuberculosis or both: A dilemma in a patient of AIDS. Indian J Sex Transm Dis AIDS. 2012; 33 (1):44-6. doi: https://doi.org/10.4103/0253-7184.93824 